\title{
Pengaruh Temperatur terhadap Karakterisasi Klinker Semen dengan Substitusi 20\% Batu Basalt terhadap Massa Batu Kapur dan 20\% Batubara terhadap Massa Total sebagai Reduktor
}

\author{
Leni Rumiyanti ${ }^{(1)^{*}}$, Yuliana Sari ${ }^{(1)}$, Muhammad Amin $^{(2)}$ \\ (1)Jurusan Fisika, FMIPA, Universitas Lampung, Bandar Lampung \\ ${ }^{(2)}$ UPT. Balai Penelitian Teknologi Mineral, LIPI, Lampung Selatan, \\ Email:lenirumiyanti@fmipa.unila.ac.id
}

Diterima (20 November 2019), Direvisi (30 Desember 2019)

\begin{abstract}
This study was conducted to determine the effect of temperature on the chemical content and crystal structure on clinker of cement with $20 \%$ substitution of basalt stone on the mass of limestone and $20 \%$ of coal against total mass. The raw material used is basalt stone from East Lampung and anthracite coal. The percentage of limestone used is $80 \%$. All raw materials are milled, sifted, then formed pellets with a diameter of $0.8-1.4 \mathrm{~cm}$. Pellets are dried at room temperature, then heated and burned with temperature variations of $1000^{\circ} \mathrm{C}, 1100^{\circ} \mathrm{C}$ and $1200^{\circ} \mathrm{C}$ for 1 hour. XRF results showed that basalt rock had a content of $\mathrm{SiO} 2+\mathrm{Al} 2 \mathrm{O} 3+\mathrm{Fe} 2 \mathrm{O} 3$ of $79.293 \%$ so that basalt could be said to have pozzolanic properties. The $\mathrm{CaO}$ content for cement clinker decreased, the results of XRF with combustion temperatures of $1000^{\circ} \mathrm{C}, 1100^{\circ} \mathrm{C}$ and $1200{ }^{\circ} \mathrm{C}$ respectively were $62,329 \%, 55,606 \%$, and $54,148 \%$. Materials A, B and C respectively were burning at $1000^{\circ} \mathrm{C}, 1100^{\circ} \mathrm{C}$, and $1200 \mathrm{oC}$ for 1 hour. The crystalline phase formed in material A is calcium iron oxide with the highest peak belonging to Ca at position $2 \theta$ which is $26.6627^{\circ}$ and another crystal phase, gehlenite, syn. The crystalline phase formed in material B is akermanite-gehlenite syn with the highest peak belonging to Ca at position $2 \theta$ which is $31.2747^{\circ}$ and other crystalline phases namely and wollastonite, ferroan 1A. While the crystalline phase formed in material $C$ is akermanite-gehlenite with the highest peak belonging to Ca at position $2 \theta$ which is $31.3051^{\circ}$ and syn and other crystalline phases namely wollastonite, ferroan $1 A$.
\end{abstract}

Keywords: clinker cement, temperature, XRF, XRD.

Abstrak. Penelitian ini dilakukan untuk menganalisis pengaruh temperatur terhadap kandungan kimia dan struktur kristal pada klinker semen dengan substitusi 20\% batu basalt terhadap massa batu kapur dan 20\% batubara terhadap massa total. Bahan baku yang digunakan adalah batu basalt yang berasal dari daerah Lampung Timur dan batubara antrasit. Persentase batu kapur yang digunakan adalah 80\%. Tahapan penelitian ini terdiri atas penyiapan bahan baku, preparasi sampel, reduksi selektif, separasi sampel, dan karakterisasi. Proses reduksi selektif menggunakan tiga variasi suhu, yaitu $1000{ }^{\circ} \mathrm{C}, 1100{ }^{\circ} \mathrm{C}$, dan $1200{ }^{\circ} \mathrm{C}$ dengan waktu tahan $1 \mathrm{jam}$. Berdasarkan hasil $X$-ray fluorescence (XRF) diketahui bahwa kandungan kimia dari tiga senyawa pada klinker semen yakni $\mathrm{SiO}_{2}, \mathrm{Al}_{2} \mathrm{O}_{3}$, dan $\mathrm{Fe}_{2} \mathrm{O}_{3}$ tidak memenuhi $70 \%$ agar dapat dikatakan memiliki sifat pozzolan, hanya mencapai $32,266 \%$ pada suhu $1000{ }^{\circ} \mathrm{C} ; 39,47 \%$ pada suhu 1100 ${ }^{\circ} \mathrm{C}$ dan $41,807 \%$ pada $1200{ }^{\circ} \mathrm{C}$. Kandungan $\mathrm{CaO}$ untuk klinker semen semakin menurun dengan pertambahan suhu, yaitu $62,329 \%$ pada suhu $1000{ }^{\circ} \mathrm{C}$; $55,606 \%$ pada suhu $1100{ }^{\circ} \mathrm{C}$; dan $54,148 \%$ pada $1200{ }^{\circ} \mathrm{C}$. Berdasarkan hasil X-Ray Diffraction (XRD) diketahui bahwa fase kristal yang terbentuk adalah calcium iron oxide, gehlenite, syn pada suhu $1000{ }^{\circ} \mathrm{C}$; akermanite-gehlenite, syn, wollastonite, ferroan $1 \mathrm{~A}$ pada suhu $1100{ }^{\circ} \mathrm{C}$; dan akermanite-gehlenite, syn, wollastonite, ferroan $1 \mathrm{~A}$ pada suhu $1200{ }^{\circ} \mathrm{C}$,

Kata kunci: Batu basalt, klinker semen, suhu, XRF, XRD. 


\section{PENDAHULUAN}

Indonesia adalah salah satu negara berkembang, sehingga pembangunan infrastrukur terus dilakukan agar tercapainya kesejahteraan rakyat. Oleh karena itu, untuk mencapai target pembangunan diperlukan semen dalam jumlah besar. Dengan demikian, kebutuhan semen dalam negeri semakin meningkat seiring dengan peningkatan pembanguan sektor properti dan sektor konstruksi. Selain itu, suatu perusahaan semen juga dituntut untuk meningkatkan kualitas semen agar mampu bersaing di pasar. Berdasarkan keputusan Menteri Pekerjaan Umum dan Perumahan Rakyat Nomor 552/KPTS/M/2016 tentang batasan penghasilan kelompok sasaran KPR bersubsidi, batasan harga jual rumah sejahtera tapak dan satuan rumah sejahtera susun, serta besaran subsidi bantuan uang muka perumahan. Menganggapi keputusan tersebut, pada tahun 2018 - 2019 dilakukan pembangunan perumahan subsidi secara besar-besaran yang berdampak pada penggunaan semen dengan jumlah yang semakin besar.

Provinsi Lampung merupakan salah satu provinsi yang memiliki batu basalt dalam jumlah yang cukup besar. Cadangan batuan basalt di Provinsi Lampung saat ini mencapai 1 milliar kubik namun belum termanfaatkan secara maksimal hanya sebatas kominusi dimensi partikel untuk campuran konstruksi. Karakterisasi batuan basalt dilakukan untuk mengetahui proses pengolahan yang tepat untuk meningkatkan nilai jual produk olahan yang dihasilkan. Sampel batuan basalt dilakukan proses analisa karakteristik menggunakan alat XRD, XRF dan OM untuk mengetahui komposisi kimia batuannya, unsur dan fasa pembentuknya dan jenis batuan basalt itu sendiri. Ditahun terakhir dari penelitian ini yaitu tahun ketiga, proses penelitian difokuskan pada aplikasi dan pemanfaatan produk yang dihasilkan agar proses peningkatan nilai tambah yang lebih tinggi dapat tercapai (BPTMLIPI, 2017).

Berdasarkan latar belakang tersebut maka dilakukan penelitian mengenai pembuatan klinker semen dengan metode pellet menggunakan bahan alternatif berupa batu basalt yang masih banyak jumlahnya di alam serta tidak melupakan kualitas klinker semen berdasarkan standar yang berlaku.

Semen pada dasarnya merupakan campuran dari kalsium silikat dan sedikit kandungan dari kalsium aluminat [2]. Semen mempunyai sifat bahan perekat yang halus dan dapat mengikat bahan-bahan padat menjadi satu kesatuan massa yang kokoh. Senyawa utama yang dibutuhkan dalam pembuatan semen adalah oksida kapur $\left(\mathrm{CaCO}_{3}\right)$, oksida silika $\left(\mathrm{SiO}_{2}\right)$, oksida alumina $\left(\mathrm{Al}_{2} \mathrm{O}_{3}\right)$, dan oksida besi $\left(\mathrm{Fe}_{2} \mathrm{O}_{3}\right)$ [3]

Semen adalah bahan konstruksi yang merupakan hydraulic binder (perekat hidraulis) yang berarti bahwa senyawa-senyawa yang terkandung didalam semen tersebut dapat bereaksi dengan air dan membentuk zat baru yang bersifat sebagai perekat terhadap batuan. Kualitas Semen berdasarkan kebutuhan pelanggan: bagaimana proses pengikatan semen, perkembangan kuat tekan, panas hidrasi, pemuaian/ penyusutan volume dan ketahanan semen terhadap pengaruh lingkungan (durability). Faktor semen sangatlah mempengaruhi karakteristik campuran mortar. Kandungan semen hidraulik yang tinggi akan memberikan banyak keuntungan, antara lain dapat membuat campuran mortar menjadi lebih kuat, lebih padat, lebih tahan air, lebih cepat mengeras dan juga memberikan rekatan yang lebih baik. Kerugiannya adalah cepatnya campuran mengeras, maka dapat menyebabkan susut kering yang lebih tinggi pula. Mortar dengan kandungan hidraulik rendah akan lebih lemeh dan mudah dalam pergerakan [4].

Silika adalah salah satu unsur utama yang terdapat dalam kerak bumi dengan rumus molekul $\mathrm{SiO}_{2}$. Silika secara alami ter- 
kandung pada pasir, krikil, batu-batuan dan sekam padi. Senyawa silika ini terdapat dalam bentuk amorf (tidak beraturan) atau polimerfisme (bentuk kristal berbeda-beda). Berdasarkan hasil penelitian menunjukkan perubahan silika amorf menjadi fasa kristal terjadi pada pemanasan sekitar $800^{\circ} \mathrm{C}$ dan optimal pada $900{ }^{\circ} \mathrm{C}$ [5], dimana sifat silika dapat dilihat pada Tabel 1.

Batu basalt adalah batuan beku aphanitic yang mempunyai kandungan kuarsa tidak lebih dari $20 \%$, kadar feldspathoid kurang dari $10 \%$ dan presentase mineral felspar dalam bentuk plagioklas sebesar $65 \%$. Batu basal berwarna abu - abu hingga hitam, bersifat keras dan padat (masif). Selain itu juga mempunyai tekstur afanatik yang tersusun dari mineral piroksin, amfibol, plagioklas dan gelas vulkanik.

Batubara adalah salah satu bahan bakar fosil. Pengertian umumnya adalah batuan sedimen yang dapat terbakar, terbentuk dari endapan organik, utamanya adalah sisa-sisa tumbuhan dan terbentuk melalui proses pembatubaraan. Unsur-unsur utamanya terdiri dari karbon, hidrogen dan oksigen. Batubara juga adalah batuan organik yang memiliki sifat-sifat fisika dan kimia yang kompleks yang dapat ditemui dalam berbagai bentuk [6].

Tabel 1. Karakteristik silika [5].

\begin{tabular}{ll}
\hline \multicolumn{1}{c}{ Kategori } & \multicolumn{1}{c}{$\begin{array}{c}\text { Karakteristik Silika } \\
\left(\mathrm{SiO}_{2}\right)\end{array}$} \\
\hline Sistem Kristal & $\begin{array}{l}\text { Tetra hedral } \\
\text { Padat }\end{array}$ \\
Bentuk & 2,6 \\
Berat Jenis $\left(\mathrm{gr} / \mathrm{cm}^{3)}\right.$ & 1610 \\
Titik lebur $\left({ }^{0} \mathrm{C}\right)$ & 2230 \\
Titik didih $\left({ }^{0} \mathrm{C}\right)$ & 650 \\
Kekerasan $\left(\mathrm{Kg} / \mathrm{mm}^{2}\right)$ & 70 \\
Kekuatan tekuk $(\mathrm{Mpa})$ & 110 \\
Kekuatan tarik $(\mathrm{Mpa})$ & $73-75$ \\
Modulus elastik $(\mathrm{Gpa})$ & 17 \\
Resistivitas $(\Omega \mathrm{mm})$ & $3,2 \times 10^{-3}$ \\
Konduktivitas termal & $3 /(\mathrm{cm} \mathrm{K})$ \\
\hline
\end{tabular}

\section{METODE PENELITIAN}

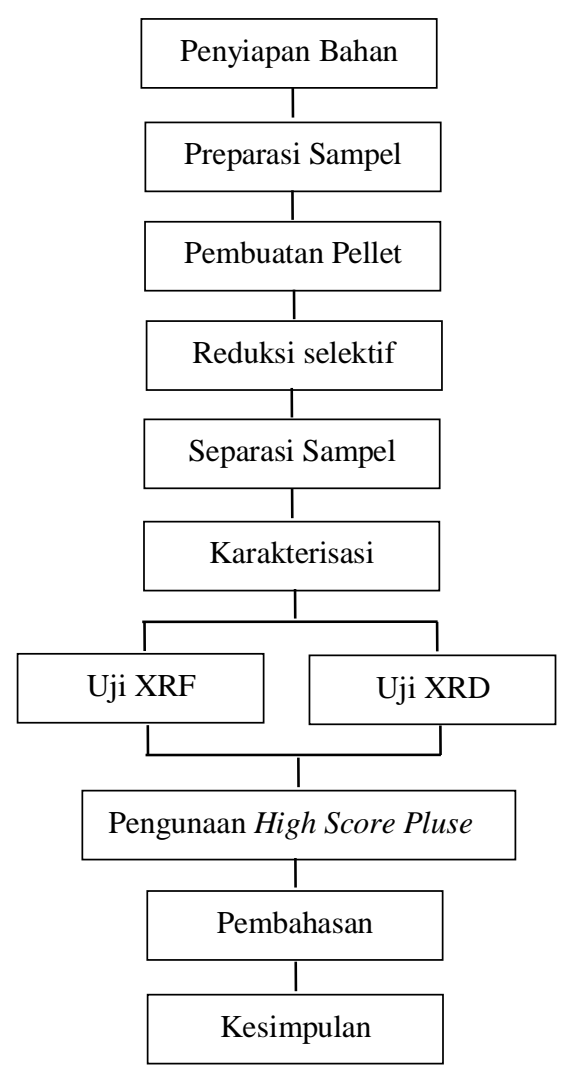

Gambar 1. Diagram alir penelitian

Proses penelitian secara keseluruhan ditunjukkan pada Gambar 1. Pada proses preparasi sampel, bahan seperti batu kapur, tanah liat, pasir silika, pasir besi, batu basalt, dan batu bara ditimbang lalu di giling dengan ball mill selama 2-3 jam. Pada proses pembuatan pellet, digunakan mesin pelletizer. Pada proses pembuatan klinker yakni klinker semen digiling dengan shaker mill selama 2 jam kemudian hasil penggilingan ditumbuk dengan menggunakan Agate mortar. Setelah klinker semen di tumbuk, klinker semen diayak sampai ukuran 270 mesh untuk dianalisis XRF untuk menentukan komposisi unsur suatu material [8] dan XRD untuk mengetahui komposisi mineral penyusun bahan [9]. Kemudian, data diolah dengan HSP. 
HASIL DAN PEMBAHASAN

Tabel 2. Hasil XRF klinker semen dengan waktu tahan kalsinasi 1 jam

\begin{tabular}{|c|c|c|c|}
\hline \multirow{3}{*}{ Komponen } & \multicolumn{3}{|c|}{ Suhu } \\
\hline & $1000^{\circ} \mathrm{C}$ & $1100^{\circ} \mathrm{C}$ & $1200^{\circ} \mathrm{C}$ \\
\hline & $\begin{array}{c}\text { Konsentrasi } \\
(\%)\end{array}$ & $\begin{array}{c}\text { Konsentrasi } \\
(\%)\end{array}$ & $\begin{array}{c}\text { Konsentrasi } \\
(\%)\end{array}$ \\
\hline $\mathrm{MgO}$ & 1,221 & 1,216 & 1,987 \\
\hline $\mathrm{Al}_{2} \mathrm{O}_{3}$ & 6,254 & 5,745 & 6,990 \\
\hline $\mathrm{SiO}_{2}$ & 19,554 & 27,194 & 27,192 \\
\hline $\mathrm{SO}_{3}$ & 1,578 & 1,084 & 0,390 \\
\hline $\mathrm{K} 2 \mathrm{O}$ & 0,212 & 0,214 & 0,482 \\
\hline $\mathrm{CaO}$ & 62,329 & 55,606 & 54,148 \\
\hline $\mathrm{TiO}_{2}$ & 0,502 & 0,553 & 0,721 \\
\hline $\mathrm{MnO}$ & 1,597 & 1,570 & 0,220 \\
\hline $\mathrm{Fe}_{2} \mathrm{O}_{3}$ & 6,458 & 6,531 & 7,625 \\
\hline
\end{tabular}

Berdasarkan Tabel 2 dapat diketahui bahwa persentase kandungan kimia tertinggi pada klinker semen adalah senyawa $\mathrm{CaO}$, yakni $62,329 \%$ pada suhu $1000{ }^{\circ} \mathrm{C} ; 55,606 \%$ pada suhu $1100{ }^{\circ} \mathrm{C}$; dan $54,148 \%$ pada suhu $1200^{\circ} \mathrm{C}$. Kandungan kimia dari tiga senyawa lainnya, yakni $\mathrm{SiO}_{2}, \mathrm{Al}_{2} \mathrm{O}_{3}$, dan $\mathrm{Fe}_{2} \mathrm{O}_{3}$ diharapkan memiliki total minimal $70 \%$ agar dapat dikatakan memiliki sifat pozzolan. Namun, pada penelitian ini hanya mencapai $32,266 \%$ pada suhu $1000{ }^{\circ} \mathrm{C}$; $39,47 \%$ pada suhu $1100{ }^{\circ} \mathrm{C}$ dan $41,807 \%$ pada $1200{ }^{\circ} \mathrm{C}$.
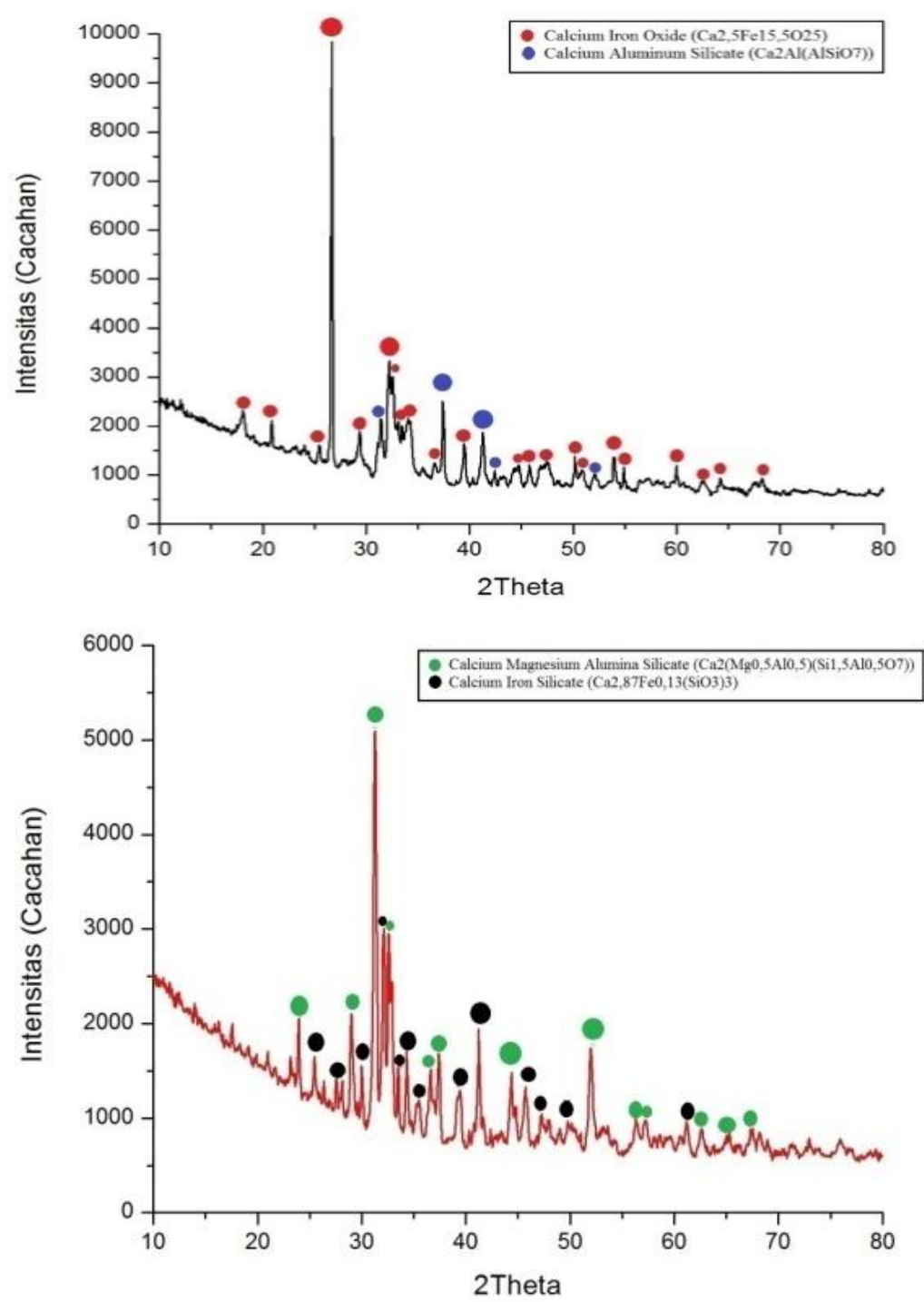

Gambar 2. Grafik data XRD klinker semen (a) pada suhu $1000{ }^{\circ} \mathrm{C}$ (atas) dan (b) pada suhu $1100^{\circ} \mathrm{C}$ (bawah) 


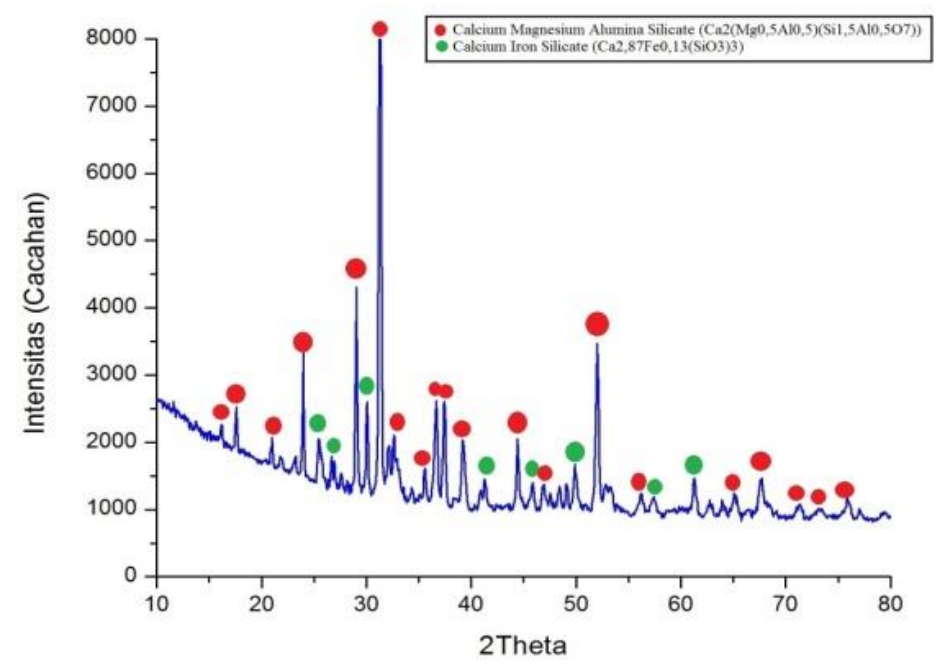

Gambar 3. Grafik data XRD klinker semen pada suhu $1200{ }^{\circ} \mathrm{C}$

Gambar 2 (a) menunjukan terbentuknya fase kristalin tertinggi pada suhu 1000 ${ }^{\circ} \mathrm{C}$ dengan pembakaran selama 1 jam. Puncak tertinggi $\mathrm{Ca}$ terbentuk pada posisi $2 \theta$ sebesar $26.6627^{\circ}$ dengan fase calcium iron oxide dimana sistem kristal berbentuk rhombohedral dan senyawa mineralnya adalah $\mathrm{Ca}_{2.5} \mathrm{Fe}_{15.5} \mathrm{O}_{25}$. Puncak $\mathrm{Ca}$ juga terbentuk pada posisi $2 \theta$ sebesar $32.1964^{\circ}$, $32.5702^{\circ}, 29.3955^{\circ}, 39.4769^{\circ}, 18.1131^{\circ}$, $20.8642^{\circ}, 25.4683^{\circ}, 34.3279^{\circ}, 33.0868^{\circ}$, $53.9341^{\circ}, 50.1664^{\circ}, 54.8945^{\circ}, 44.7463^{\circ}$, $68.2803^{\circ}, 64.2185^{\circ}, 62.4601^{\circ}, 50.9078^{\circ}$, $45.7946^{\circ}, 47.5157^{\circ}$, dan $36.5898^{\circ}$. Fase kristal lain yang terbentuk adalah Gehlenite, syn, dimana sistem kristal tetragonal dengan senyawa mineralnya adalah $\mathrm{Ca}_{2} \mathrm{Al}\left(\mathrm{AlSiO}_{7}\right)$ pada posisi $2 \theta$ sebesar $\quad 37.412^{\circ}, \quad 41.2478^{\circ}, \quad 31.43^{\circ}$, $52.0342^{\circ}$, dan $42.4225^{\circ}$.

Gambar 2 (b) menunjukan terbentuknya fase kristalin tertinggi pada suhu 1100 ${ }^{\circ} \mathrm{C}$ dengan pembakaran selama 1 jam. Puncak tertinggi $\mathrm{Ca}$ terbentuk pada posisi $2 \theta$ sebesar $31.2747^{\circ}$ dengan fase akermanite-gehlenite, syn, dimana sistem kristal berbentuk tetragonal dan senyawa mineralnya adalah $\mathrm{Ca}_{2}\left(\mathrm{Mg}_{0,5} \mathrm{Al}_{0,5}\right)$ $\left(\mathrm{Si}_{1,5} \mathrm{Al}_{0,5} \mathrm{O}_{7}\right.$. Puncak $\mathrm{Ca}$ juga terbentuk pada posisi $2 \theta$ sebesar $32.5824^{\circ}, 29.0094^{\circ}$, $51.982^{\circ}, 23.9478^{\circ}, 37.3972^{\circ}, 36.5967^{\circ}$, $44.3737^{\circ}, 56.3602^{\circ}, 57.2754^{\circ}, 67.4683^{\circ}$, $65.2554^{\circ}$, dan $62.6294^{\circ}$. Fase kristal lain yang terbentuk adalah wollastonite, ferroan $1 A$, dimana sistem kristal anorthic dengan senyawa mineralnya adalah $\mathrm{Ca}_{2.87} \mathrm{Fe}_{0.13}$ $\left(\mathrm{SiO}_{3}\right)_{3}$ pada posisi $2 \theta$ sebesar $32.1138^{\circ}$, $30^{\circ}, \quad 41.2255^{\circ}, \quad 33.5052^{\circ}, \quad 34.3258^{\circ}$, $39.4866^{\circ}, 45.8087^{\circ}, 25.4388^{\circ}, 35.5593^{\circ}$, $61.2026^{\circ}, \quad 47.2075^{\circ}, \quad 27.5669^{\circ}, \quad$ dan $49.7675^{\circ}$.

Gambar 3 menunjukan terbentuknya fase kristalin tertinggi pada suhu $1200{ }^{\circ} \mathrm{C}$ dengan pembakaran selama 1 jam. Puncak tertinggi $\mathrm{Ca}$ terbentuk pada posisi $2 \theta$ sebesar $31.3051^{\circ}$ dengan fase akermanitegehlenite, syn, dimana sistem kristal berbentuk tetragonal dan senyawa mineralnya adalah $\mathrm{Ca}_{2}\left(\mathrm{Mg}_{0,5} \mathrm{Al}_{0,5}\right)$ $\left(\mathrm{Si}_{1,5} \mathrm{Al}_{0,5} \mathrm{O}_{7}\right)$. Puncak $\mathrm{Ca}$ juga terbentuk pada posisi $2 \theta$ sebesar $29.0422^{\circ}, 23.978^{\circ}$, $36.656^{\circ}, 37.4204^{\circ}, 39.1681^{\circ}, 44.4074^{\circ}$, $52.013^{\circ}, \quad 67.7585^{\circ}, \quad 65.149^{\circ}, \quad 17.5876^{\circ}$, $21.0053^{\circ}, 32.6128^{\circ}, 35.5851^{\circ}, 75.9534^{\circ}$, $56.2314^{\circ}, 46.8785^{\circ}, 71.4123^{\circ}, 73.5017^{\circ}$, dan $16.1522^{\circ}$. Fase kristal lain yang terbentuk adalah wollastonite, ferroan $1 A$, dimana sistem kristal anorthic dan senyawa mineralnya adalah $\mathrm{Ca}_{2.87} \mathrm{Fe}_{0.13}\left(\mathrm{SiO}_{3}\right)_{3}$ pada posisi $2 \theta$ sebesar $49.881^{\circ}, 61.2596^{\circ}$, $30.0637^{\circ}, 25.448^{\circ}, 41.2992^{\circ}, 45.8498^{\circ}$, $57.4016^{\circ}$, dan $26.9408^{\circ}$. 


\section{KESIMPULAN}

Berdasarkan pada pembahasan dapat disimpulkan bahwa kandungan kimia dari tiga senyawa pada klinker semen yakni $\mathrm{SiO}_{2}, \mathrm{Al}_{2} \mathrm{O}_{3}$, dan $\mathrm{Fe}_{2} \mathrm{O}_{3}$ tidak memenuhi $70 \%$ agar dapat dikatakan memiliki sifat pozzolan, hanya mencapai $32,266 \%$ pada suhu $1000{ }^{\circ} \mathrm{C} ; 39,47 \%$ pada suhu $1100{ }^{\circ} \mathrm{C}$ dan $41,807 \%$ pada $1200{ }^{\circ} \mathrm{C}$. Kandungan $\mathrm{CaO}$ untuk klinker semen semakin menurun dengan pertambahan suhu, yaitu 62,329\% pada suhu $1000{ }^{\circ} \mathrm{C} ; 55,606 \%$ pada suhu $1100{ }^{\circ} \mathrm{C}$; dan $54,148 \%$ pada $1200{ }^{\circ} \mathrm{C}$. Fase kristal yang terbentuk pada suhu $1000{ }^{\circ} \mathrm{C}$, $1100{ }^{\circ} \mathrm{C}$, dan $1200{ }^{\circ} \mathrm{C}$ berturut-turut adalah calcium iron oxide dan gehlenite, syn; akermanite-gehlenite, syn dan wollastonite, ferroan 1A; dan akermanite-gehlenite, syn dan wollastonite, ferroan $1 A$.

\section{DAFTAR PUSTAKA}

[1] M. Amin, "Pembuatan semen geopolimer ramah lingkungan berbahan baku mineral basal guna menuju lampung sejahtera," J. Inov. Pembang., vol. 05 No. 01, 2017.

[2] T. Ningsih, R. Chairunnisa, and S. Miskah, "Pemanfaatan Bahan Additive Abu Sekam Padi pada Semen Portland PT. Semen Baturaja (Persero)," Jur. Tek. Kim. Fak. Tek. Univ. Sriwij., vol. 18, pp. 59-67, 2012.

[3] I. W. Intara, D. Age, A. Of, C. Compressive, O. F. Opc, and P. C. C. C. Paste, "Perbedaan Umur Pencapaian Kuat Tekan Beton Dari Perekat Semen Opc , Ppc Dan Pcc Difference Age Achievement of Concrete Compressive Strength of Opc , Ppc and Pcc Cement Paste," vol. 14, no. 2, pp. 82-86, 2014.

[4] E. Khikmawati, M. Anggraini, and K. Anwar, "Analisis Perencanaan Biaya Persediaan Produk Semen Melalui Pendekatan Perencanaan Kebutuhan Bahan Baku (Material Requirement
Planning)," J. Rekayasa Teknol. dan sains, vol. 1, no. 1, pp. 28-35, 2017.

[5] L. F. Aprida, D. Dermawan, and R. Bayuaji, "Identifikasi Potensi Pemanfaatan Limbah Karbit dan Abu Sekam Padi sebagai Bahan Alternatif Pengganti Semen," no. 2623, pp. 20132016, 2015.

[6] I. M. Suparta, I. M. Alit, K. Salain, And M. Anom, "Sifat Mekanis Beton Dengan Substitusi Parsial Serbuk Batu Bata Pada Semen Portland Mechanical Properties Of Concrete With Brick Powder As A Partial Substitution Of Portland Cement," Vol. 6, No. 1, Pp. 117-125, 2018.

[7] F. E. Putri and R. Abdullah, "Kajian Teknis Produktivitas Dan Efisiensi Kerja Belt Conveyor Dalam Pengiriman Limestone \& Silicastone Ke Storage Indarung Pada Pt . Semen Padang Sumatera Barat," vol. 3, no. 3, pp. 10781090, 2020.

[8] W. D. Puspitasari, F. Setyono, and G. S. Budi, "Pengaruh Penambahan Fly Ash Dan Bubuk Kulit Kerang," pp. 297-303.

[9] I. Satyarno, "Penggunaan Semen Putih untuk Beton Styrofoam Ringan (BATAFOAM)," Lap. Penelit. Lab. Konstr. Jur. Tek. Sipil, Fak. Tek. Univ. Gadjah Mada, Yogyakarta, no. February, 2004. 